\title{
Aditivos na Conservação do Bagaço de Laranja in natura na Forma de Silagem ${ }^{1}$ \\ Luís Carlos Vinhas Ítavo², Geraldo Tadeu dos Santos ${ }^{3 *}$, Clóves Cabreira Jobim, Tadeu Vinhas Voltolini ${ }^{4}$, João Ricardo Bortolassi ${ }^{4}$, Camila Celeste Brandão Ferreira ${ }^{5}$
}

RESUMO - Estudaram-se os efeitos de aditivos na fermentação e composição do bagaço de laranja, em silos laboratoriais de PVC com capacidade para $15 \mathrm{~kg}$, distribuídos ao acaso com três silos por tratamento: sem aditivo (CT), inoculante enzimático microbiano (IN) e ácidos fórmico (FO), propiônico (PP) e acético (AC). As amostras foram tomadas antes (0) e 2, 8, 16, 32 e 64 dias após a ensilagem. Analisaram-se os teores de matéria seca (MS), proteína bruta (PB), fibra em detergente neutro (FDN) e detergente ácido (FDA), a digestibilidade in vitro da matéria seca (DIVMS) e da parede celular (DIVPC), o pH, a capacidade tampão (CATP) e o N amoniacal. A silagem sem aditivo apresentou os menores teores de MS. Os teores de PB, FDN e FDA da silagem tratada com ácido fórmico (FO) foram os menores. As DIVMS e DIVPC foram constantes, com exceção do tratamento com ácido fórmico (FO), que foi linear negativo, em função do tempo de ensilado. O comportamento do $\mathrm{pH}$ apresentou equações de regressão cúbicas, com exceção do tratamento com ácido fórmico, que foi linear. A silagem tratada com ácido fórmico apresentou os menores valores de CATP (25,7 a 39,1 mg HCl/100 g MS) e os maiores de $\mathrm{N}$ amoniacal ( 3 a $4 \% \mathrm{~N}$ total). Os aditivos não melhoraram a qualidade e o valor nutricional da silagem de bagaço de laranja

Palavras-chave: aditivos, bagaço de laranja, silagem

\section{Conservation of Fresh Orange Peel by Ensilage Process using Additives}

\begin{abstract}
The objective of this experiment was to study the effects of different additives on fermentation and composition of orange peel silage. Fresh orange peel was ensiled in 15-kg capacity PVC laboratory silos that were arranged according to a randomized design with three silos per treatment: without additive (control), enzyme inoculate (EI), formic acid (FA), propionic acid (PA) and acetic acid (AA). Samples of orange peel were taken before ensiling (0), and 2, 8, 16, 32 and 64 days after ensiling. Samples of fresh and ensiled orange peel were analyzed for dry matter (DM), crude protein (CP), neutral detergent fiber (NDF), acid detergent fiber (ADF), in vitro dry matter disappearance (IVDMD), in vitro cell wall disappearance (IVCWD), $\mathrm{pH}$, buffering capacity and ammonia $\mathrm{N}$. The control silage had the lowest DM values (12.2\%). Percentages of CP, NDF and ADF of FA silage were lower than those of the other silages. The IVDMD and IVCWD did not change, but FA silage was linear negative in function of days after ensiling. The pH presented cubic regression comportment, except for the treatment with formic acid, that was linear. The FA silage had the lowest buffering capacity (25.7 to $39.1 \mathrm{meq}$ of $\mathrm{HCl} / 100 \mathrm{~g}$ of $\mathrm{DM}$ ) and the greatest ammonia $\mathrm{N}$ values (3.0 to $4.0 \%$ of total $\mathrm{N}$ ). Additives do not improve the quality and nutritional value of orange peel silage.
\end{abstract}

Key Words: additives, orange peel, silage

\section{Introdução}

Segundo Bravermann, (1949) citado por ASHBELL et al. (1987) o valor nutricional do bagaço de laranja, com base na matéria seca, é alto. Contudo, quando úmido, deteriora-se rapidamente durante a estocagem e perde o valor nutritivo, algumas vezes em mais de 50\% (ASHBELL e WEINBERG, 1988), havendoa necessidade de se desenvolverem metodologias para conservá-lo e melhorar a sua estabilidade.

A indústria de suco de laranja produz como subproduto o bagaço de laranja, que compreende
$42 \%$ do total da fruta (casca, sementes e porção tegumentar), segundo a COCAMAR CITRUS S/A. Seu valor para a alimentação de ruminantes é semelhante aos grãos, com valores médios de NDT, PB, FDN, FDA, lignina e digestibilidade aparente da matéria seca, respectivamente, de 83 a $88 \% ; 7,0 ; 23$; 22; 3; e 84-90\% (ASHBELL, 1992; VAN SOEST, 1994; e ÍTAVO et al., 1998). A maior digestibilidade de algumas frações da fibra do bagaço de laranja é atribuída especialmente a seu alto teor de carboidratos solúveis e pectina, os quais são os responsáveis pela elevada digestibilidade das silagens (PERES, 1997),

\footnotetext{
1 Parte da Dissertação de Mestrado apresentada pelo primeiro autor ao MZO/CCA-Universidade Estadual de Maringá

2 Zootecnista, M.Sc., Professor do Curso de Zootecnia da Universidade Católica Dom Bosco - UCDB, Campo Grande - MS .E.mail: itavo@ucdb.br

3 Professor do DZO/CCA - UEM, Av.Colombo, 5790.CEP 87.020-900, Maringá,PR *Bolsista do CNPq.E.mail: gtsantos@uem.br; ccjobim@uem.br

4 Aluno do curso de Zootecnia/UEM - Maringá, PR.

5 Aluna do curso de Zootecnia/UFV - Viçosa, MG.
} 
comprovada pelos coeficientes de digestibilidade aparente dos carboidratos não-estruturais, que foram, em média, 89,2\% (ÍTAVO et al., 1998).

No entanto, o bagaço de laranja produzido em diferentes locais pode variar consideravelmente quanto à composição química, à palatabilidade e ao valor nutritivo (BRANCO et al., 1994). As diferenças nos processos de desidratação, fontes e variedades das frutas e o tipo de operação pelo qual o resíduo da fruta é obtido podem resultar em variações no conteúdo de nutrientes do subproduto final (AMMERMAN e HENRY, 1991), além da extração ou não dos óleos essenciais.

A prática de desidratar o bagaço de laranja é comum na grandes empresas esmagadoras de laranja, tendo como produto comercial o bagaço de laranja desidratado e peletizado, erroneamente denominado "polpa de citrus". Devido ao alto custo de energia, muitas vezes esta tecnologia se torna antieconômica. A ensilagem é outro método de conservação utilizada, porém, devido às perdas inerentes ao processo, fazse necessário rever esta tecnologia de conservação, em bases econômicas.

Apesar de se obterem silagens de boa qualidade, deve-se destacar que o bagaço de laranja não poderia ser considerado como um material adequado a esse processo de conservação, devido ao baixo teor de matéria seca. A umidade excessiva provocará perdas significativas de nutrientes e encarecimento do transporte (FARIA et al., 1971), além das perdas por proteólise e aquelas provocadas por clostrídios e leveduras (ROTZ e MUCK, 1994).

O ácido fórmico tem efeito desidratante, inibe seletivamente algumas bactérias, não inibe a fermentação láctica e promove rápida diminuição inicial do $\mathrm{pH}$, tornando o ambiente propício ao desenvolvimento de Lactobacillus spp. (RUIZ e MUNARI, 1992). O bagaço de laranja ensilado em tubos de concreto com capacidade de $700 \mathrm{~kg}$ de material natural, utilizando o ácido fórmico como aditivo, segundo ÍTAVO et al. (1998), apresentou os menores valores de NIDA (3,90\% do $\mathrm{N}$ total) e, conseqüentemente, conservou maior quantidade de carboidratos não-estruturais, em relação ao tratamento sem aditivos, porém não houve diferenças quanto aos coeficientes de digestibilidade aparente. MEGÍAS et al. (1993) verificaram que o alto conteúdo inicial de água no bagaço de laranja, resultante do processamento industrial para obtenção do produto, afetou a qualidade do bagaço ensilado, sugerindo um tratamento de secagem ou condicionamento do material, antes da ensilagem. Porém, estu- dos sobre o uso de aditivos na composição e digestibilidade aparente da silagem de bagaço de laranja demonstraram que o subproduto da indústria de suco de laranja dispensaria o uso de aditivos (ÍTAVO et al., 1998), discordando de ASHBELL e WEINBERG (1988) e MEGÍAS et al. (1993), que relataram que, para ensilar o bagaço de laranja, é necessário melhorar as condições para a fermentação, a fim de reduzir as perdas na ensilagem, caracterizando as diferenças regionais e de processamento para a obtenção do subproduto.

$\mathrm{O}$ uso de inoculantes tem melhorado a qualidade fermentativa de silagens, principalmente pela redução do ácido acético e N amoniacal (GORDON, 1996), porém ÍTAVO et al. (1998) não encontraram diferenças quanto ao NIDA da silagem de bagaço de laranja tratado com inoculante enzimático microbiano, em relação à silagem de bagaço de laranja sem aditivos. GORDON (1996) estudou o efeito de aditivos de silagem no desempenho animal e sugeriu que os tratamentos com ácido fórmico propiciaram valores mais elevados para a digestibilidade in vitro da matéria seca em relação às silagens não-tratadas. Destaca-se que o bagaço de laranja é caracterizado pela alta digestibilidade da MS (VAN SOEST, 1994; CARVALHO, 1995; e ÍTAVO et al. 1998).

WEINBERG (1992) comentou que muitos subprodutos podem ser conservados por ensilagem, entre eles o bagaço de laranja. A tecnologia empregada deve ser adequada às características do subproduto, como alto conteúdo de umidade, por exemplo. A melhor solução seria combinar a conservação com as vantagens nutricionais. O conhecimento químico e microbiológico dos subprodutos podem ser de grande ajuda para encontrar tais soluções. Dessa forma, objetivou-se, com o experimento, determinar a composição e as características fermentativas do bagaço de laranja ensilado com diferentes aditivos, além da digestibilidade in vitro da matéria seca e da parede celular das silagens, em função do dia de abertura dos silos.

\section{Material e Métodos}

O trabalho foi conduzido na Fazenda Experimental de Iguatemi, no Laboratório de Análises de Alimentos e Nutrição Animal e no Laboratório de Metabolismo Animal do Departamento de Zootecnia da Universidade Estadual de Maringá.

O bagaço de laranja obtido da COCAMAR CITRUS S/A., após a extração do óleo essencial da casca, foi ensilado em silos experimentais de PVC 
1476 Rev. bras. zootec.

com diâmetro de $200 \mathrm{~mm}$ e $49 \mathrm{~cm}$ de comprimento, com capacidade de aproximadamente $15 \mathrm{~kg}$.

Os tratamentos constaram da adição dos aditivos ao material natural que foi ensilado, diluídos em água (com base na matéria natural - MN) como segue: (IN) bagaço de laranja + aditivo enzimático microbiano\# (200g/t de MN); (FO) bagaço de laranja + ácido fórmico a $10 \%$ (40 mL/kg de $\mathrm{MN})$; (PP) bagaço de laranja + ácido propiônico a $10 \%(10 \mathrm{~mL} /$ $\mathrm{kg}$ de $\mathrm{MN}$ ); (AC) bagaço de laranja + ácido acético a $10 \%(10 \mathrm{~mL} / \mathrm{kg}$ de $\mathrm{MN})$; (CT) bagaço de laranja sem aditivo (Controle), arranjados em delineamento experimental inteiramente casualizado em esquema fatorial 5 x 6, com três repetições, para cada período de amostragem. Foram realizadas amostragens antes da ensilagem (0) e aos 2, 8, 16, 32 e 64 dias após o fechamento dos silos.

As amostras para as análises do bagaço de laranja, antes da ensilagem, foram coletadas logo após a aplicação do aditivo, enquanto o bagaço in natura foi coletado imediatamente após a chegada do material no local do experimento, isento de qualquer aditivo. Para cada tratamento e cada tempo de abertura dos silos, foram determinados os valores para matéria seca (MS) e proteína bruta (PB), segundo SILVA (1990), fibra em detergente neutro (FDN), fibra em detergente ácido (FDA) e digestibilidade in vitro da parede celular (DIVPC) e da matéria seca (DIVMS), segundo GOERING e VAN SOEST (1970), e capacidade tampão, $\mathrm{N}$ amoniacal e $\mathrm{pH}$ das silagens, conforme PLAYNE e McDONALD (1966).

Para as análises de digestibilidade, utilizou-se o fermentador ruminal denominado DaisyII de ANKOM - Technology Corporation - EUA, descrito por SANTOS et al. (1997). Para a DIVPC, os resíduos foram submetidos à determinação da FDN no analisador de fibra, pelo procedimento modificado de GOERING e VAN SOEST (1970). Foi utilizado material présecado a $55^{\circ} \mathrm{C}$ em estufa de ventilação forçada. A quantidade de material das silagem estudadas foi a indicada pelo método, $0,5 \mathrm{~g}$ de material. Ainda foram incubados sacos lacrados sem material (branco), para correções de contaminação. Para a coleta do líquido ruminal, foi utilizada uma vaca da raça Holandês $\mathrm{P} \& \mathrm{~B}$, multípara, munida de fístula ruminal, recebendo ração total misturada à base de silagem de bagaço de laranja, silagem de milho, concentrado e minerais. A vaca fistulada foi adaptada à alimentação 14 dias anterior à coleta de líquido ruminal, alimentada três vezes ao dia ( $7 \mathrm{~h} 30,12 \mathrm{~h} 30 \mathrm{e} 16 \mathrm{~h})$ e mantida confinada durante a realização da digestibilidade in vitro.

O modelo matricial utilizado foi:

$$
\underline{\mathbf{Y}}=\mathbf{X} \underline{\boldsymbol{\beta}}+\boldsymbol{\varepsilon}
$$

em que $\underline{\mathbf{Y}}$ é o vetor dos valores observados ( $\mathrm{N}$ x 1); $\mathbf{X}$, a matriz correspondente aos valores das variáveis independentes $(\mathrm{N} \times \mathrm{PH}) ; \boldsymbol{\beta}$, o vetor de parâmetros desconhecidos ( $\mathrm{PH}$ x 1); $\boldsymbol{\varepsilon}$, o vetor de erros aleatórios ( $\mathrm{N}$ x 1$)$, em que $\boldsymbol{\varepsilon} \sim \mathrm{N}\left(\phi, I \sigma^{2}\right)$; P, o número de parâmetros por modelo, incluindo b0; e N, o número total de observações, considerando $\mathrm{H}$ modelos.

Foi utilizado o teste para verificar a identidade dos modelos de regressão obtidos, segundo REGAZZI (1993), com significância em $\mathrm{P}<0,05$. Quando se compararam médias observadas entre tratamentos, dentro de dias de abertura dos silos, utilizou-se o teste Tukey a $5 \%$.

\section{Resultados e Discussão}

Na Tabela 1, estão apresentadas as equações de regressão ajustadas para os teores de MS, em função do tempo de ensilagem, em dias. O conteúdo de

Tabela 1 - Equações de regressão ajustadas para os teores de MS da silagem de bagaço de laranja tratada ou não com aditivos, em função do dia (d) de abertura dos silos experimentais

Table 1 - Fitted regression equations for the orange peel DM silage with or without additives, in function of the open day (d) of the experimental silos

\begin{tabular}{lcr}
\hline $\begin{array}{l}\text { Tratamento } \\
\text { Treatment }\end{array}$ & \multicolumn{1}{c}{$\begin{array}{c}\text { Equações de regressão } \\
\text { Regression equations }\end{array}$} & $\mathrm{R}^{2}$ \\
\hline IN & $\hat{\mathrm{Y}}=14,3335-0,0682257 \mathrm{~d}+0,000805498 \mathrm{~d}^{2}$ & 0,83 \\
FO & $\hat{\mathrm{Y}}=15,2859+0,088987 \mathrm{~d}-0,00630074 \mathrm{~d}^{2}+0,0000743043 \mathrm{~d}^{3}$ & 0,70 \\
PP & $\hat{\mathrm{Y}}=14,3073-0,0691210 \mathrm{~d}+0,00102151 \mathrm{~d}^{2}$ & 0,88 \\
AC & $\hat{\mathrm{Y}}=14,9851-0,0917536 \mathrm{~d}+0,00116958 \mathrm{~d}^{2}$ & 0,79 \\
CT & $\hat{\mathrm{Y}}=12,6508+0,246693 \mathrm{~d}-0,0106476 \mathrm{~d}^{2}+0,000108049 \mathrm{~d}^{3}$ & 0,70 \\
\hline
\end{tabular}

$\mathrm{IN}=$ inoculante enzimático microbiano; $\mathrm{FO}$ = ácido fórmico; $\mathrm{PP}$ = ácido propiônico; $\mathrm{AC}$ = ácido acético; $\mathrm{CT}=$ controle, sem aditivo

$I N=$ microbial enzymatic additive $F O=$ formic acid $; P P=$ propionic acid $; A C=$ acetic acid; $C T=$ Control, without additive 
matéria seca (MS) do bagaço de laranja in natura, antes de ensilado, sem aditivo, foi o menor, $12,1 \%$ $(\mathrm{P}<0,05)$, caracterizando o produto como muito úmido. Os outros tratamentos tiveram valores maiores $(\mathrm{P}<0,05)$, em média 14,6, podendo-se inferir que já houve ação desidratante dos aditivos ácidos, logo após a sua aplicação, o que pode ser observado pelas equações de regressões ajustadas para a MS, em função dos dias de abertura dos silos. Todavia, para o bagaço com inoculante enzimático microbiano, este falto não se aplicaria, uma vez que, provavelmente, o aumento na MS poderia ser causado pela lixiviação de compostos solúveis, além de água.

O tratamento com ácido fórmico (FO) promoveu, de modo geral, maior desidratação no bagaço de laranja, a partir do momento da aplicação, havendo diferença $(\mathrm{P}<0,05)$ no conteúdo de MS em relação aos demais tratamentos, concordando com RUIZ e MUNARI (1992), os quais afirmam que o ácido fórmico, quando utilizado como aditivo na ensilagem, tem função desidratante e, conseqüentemente, aumenta o conteúdo de MS do material, porém o tratamento com ácido acético (AC) também apresentou rápida desidratação, o que também foi verificado por ÍTAVO et al. (1998), que analisaram a composição bromatológica do bagaço de laranja ensilado em tubos de concreto, por 70 dias.

A variação das características nutricionais e fermentativas antes e durante o processo de fermentação, na ensilagem do bagaço de laranja, foi apresentada por ASHBELL e DONAHAYE (1984) e MEGÍAS et al. (1993). A composição do bagaço antes da ensilagem variou de 13,5 a $21,6 \%$ de MS, 5, 1 a $6,4 \%$ de PB, $13 \%$ de FDN, $12,9 \%$ de FDA e 2,5 a $3,8 \%$ de cinzas e, após a ensilagem, de 12,4 a 22,1\% de MS, 8,3 a $8,4 \%$ de PB, 23,4\% de FDN, $17,1 \%$ de FDA e 4,1 a $4,2 \%$ de cinzas, com base na MS. Tais variações provavelmente são referentes a perdas de nutrientes solúveis. O bagaço de laranja geralmente contém entre 12 e $22 \%$ de matéria seca e, durante o processo de fermentação, mais de $22 \%$ do peso do bagaço fresco pode ser perdido pela lixiviação (ASHBELL e DONAHAYE, 1986). Os teores de MS da silagem sem aditivo (CT) estão de acordo com FARIA et al. (1971), que encontraram 12,8\% de teor de MS para o bagaço de laranja ensilado em sacos plásticos.

$\mathrm{O}$ tratamento com ácido fórmico (FO) obteve o maior valor $(\mathrm{P}<0,05)$ para os teores de $\mathrm{MS}$, sugerindo que o tratamento pode ter produzido mais efluente $\mathrm{e}$, consequientemente, ocorrido perdas de MS, ou provavelmente, de água, pois o ácido fórmico exerce efeito desidratante sobre os materiais úmidos (RUIZ e MUNARI, 1992). Quando se substituíram os valores (d) nas equações de regressão, observou-se que o tratamento sem aditivo permaneceu inferior aos demais após o $32^{\mathrm{o}}$ dia de ensilagem, confirmando o efeito desidratante dos ácidos, pois estes tratamentos já iniciaram com teores mais elevados de MS. De forma geral, o comportamento ocorreu de forma quadrática e cúbica, mas deve-se destacar que isso provavelmente é devido à variação dos dados, permitindo o ajuste desses modelos. O comportamento esperado para o teor MS, entretanto, seria linear, isto é, dentro de um compartimento hermeticamente fechado, tal como o silo, não haveria maneira de aumentar o conteúdo de MS das silagens.

Os valores referentes à PB (Tabela 2), antes da ensilagem, diferiram entre si $(\mathrm{P}<0,05)$. A PB do tratamento sem aditivo (CT) foi a maior (7\%), em relação àquela dos demais tratamentos, provavel-

Tabela 2 - Equações de regressão ajustadas para os teores de PB da silagem de bagaço de laranja tratada ou não com aditivos, em função do dia (d) de abertura dos silos experimentais (\% MS)

Table 2 - Fitted regression equations for orange peel silage $C P$, with or without additives, in function of the open day (d) of the experimental silos (\% DM)

\begin{tabular}{lcr}
\hline $\begin{array}{l}\text { Tratamento } \\
\text { Treatment }\end{array}$ & $\begin{array}{c}\text { Equações de regressão } \\
\text { Regression equations }\end{array}$ & $\mathrm{R}^{2}$ \\
\hline $\mathrm{IN}$ & $\hat{\mathrm{Y}}=6,57109+0,107438 \mathrm{~d}-0,0050975 \mathrm{~d}^{2}+0,0000534066 \mathrm{~d}^{3}$ & 0,97 \\
$\mathrm{FO}$ & $\hat{\mathrm{Y}}=5,96254+0,0524181 \mathrm{~d}-0,0031879 \mathrm{~d}^{2}+0,0000350239 \mathrm{~d}^{3}$ & 0,95 \\
$\mathrm{PP}$ & $\hat{\mathrm{Y}}=6,46439+0,0945131 \mathrm{~d}-0,00440566 \mathrm{~d}^{2}+0,0000459471 \mathrm{~d}^{3}$ & 0,81 \\
$\mathrm{AC}$ & $\hat{\mathrm{Y}}=6,22878+0,0440922 \mathrm{~d}-0,00146556 \mathrm{~d}^{2}+0,0000134237 \mathrm{~d}^{3}$ & 0,76 \\
$\mathrm{CT}$ & $\hat{\mathrm{Y}}=6,99121+0,02460431 \mathrm{~d}-0,00217127 \mathrm{~d}^{2}+0,000026004 \mathrm{~d}^{3}$ & 0,93 \\
\hline $\mathrm{N}=$ inoculante enzimático microbiano; $\mathrm{FO}=$ ácido fórmico; $\mathrm{PP}=$ ácido propiônico; $\mathrm{AC}=$ ácido acético; \\
$\mathrm{CT}=$ controle, sem aditivo. \\
IN = microbial enzymatic additive; $F O=$ formic acid; $P P=$ propionic acid; $A C=$ acetic acid; $C T=$ Control, without additive.
\end{tabular}


1478 Rev. bras. zootec.

mente devido ao efeito de diluição do material in natura com os tratamentos realizados em solução aquosa. Estes resultados estão de acordo com VAN SOEST (1994), BRANCO et al. (1994) e ÍTAVO et al. (1998), os quais apresentaram, valores médios entre 7 e $8 \%$ de PB para o bagaço de laranja ensilado ou in natura.

$\mathrm{O}$ tratamento com ácido fórmico (FO), comparado aos demais, foi o que apresentou menores valores para $\mathrm{PB}(\mathrm{P}<0,05)$. As silagens sem aditivo $(\mathrm{CT})$, com inoculante microbiano (IN) e com ácido propiônico (PP) foram as que apresentaram maiores valores para $\mathrm{PB}(\mathrm{P}<0,05)$, aos 2 e 8 dias de ensilagem, com os valores entre 6,8 e $7 \%$ e 7,1 a $7,2 \%$, respectivamente. Após 16 dias do fechamento dos silos, substituindo-se na equação de regressão $(\mathrm{d}=16)$, o tratamento com aditivo enzimático microbiano (IN) apresentou $7,2 \%$ de PB, sendo o tratamento que apresentou nesse tempo de abertura do silo o valor mais elevado, enquanto os valores dos tratamentos de PP, CT e AC estavam entre 6,6 e 7,0. MORRISON (1966) encontrou valores de 6,9\% de PB para polpa de laranja fresca, semelhantes aos obtidos no presente experimento, porém Becker e Dix Arnould (1951), citados por FARIA et al. (1971), argumentaram que o valor protéico do bagaço de laranja pode oscilar de acordo com a variedade ou com o aproveitamento ou não das sementes para a extração de óleo e, quanto maior for a quantidade de sementes, mais elevado será o teor de proteína do subproduto. FARIA et al. (1971) encontraram valores médios de 9,6\% de PB para o bagaço de laranja antes de ensilado.

Os valores referentes à MS e PB das silagens tratadas ou não com aditivos (Tabelas 1 e 2) foram inferiores ao apresentados por MEGÍAS et al. (1993), pois o conteúdo de MS do bagaço de laranja sem aditivos (CT), substituindo-se na equação de regressão ( $d=0$; antes de ensilado), foram 12,12 e 6,99\% de PB e, após 64 dias de ensilagem, 13,15\% de MS e $6,49 \%$ de PB, concordando com os resultados de ASHBELL e DONAHAYE (1984), em que as composições para o bagaço antes da ensilagem foram: $13,5 \%$ de MS e 6,4\% de PB. Resultados superiores foram apontados por MEGÍAS et al. (1993), 21,6\% de MS antes da ensilagem e 22,1\% de MS após 100 dias.

Os teores de PB do bagaço in natura foram maiores que os obtidos por MEGÍAS et al. (1993), porém menores apresentados por ASHBELL e DONAHAYE (1984), 8,3\% de PB após 90 dias de ensilagem, demonstrando a discrepância dos resultados de análises do bagaço de laranja, justificada pelos diferentes processos realizados entre as esmagadoras, pois algumas podem retirar as sementes, ou ainda extrair óleos essenciais. As diferenças entre os subprodutos obtidos da indústria de suco de laranja, além da hipótese de ter ocorrido proteólise nessas silagens e, conseqüentemente, perdas de $\mathrm{N}$, já foram enumeradas por AMMERMAN e HENRY (1991). Todavia, deve-se se destacar que pequenas variações nos teores de PB podem indicar que os aditivos foram eficientes para reduzir a degradação protéica, fato evidenciado pelos valores extremamente baixos de $\mathrm{pH}$ e $\mathrm{N}$ amoniacal, também caracterizado por valores de NIDA da silagem de bagaço de laranja, apresentados por ÍTAVO et al. (1998).

Os valores médios da FDN, encontrados para o bagaço de laranja antes da ensilagem, praticamente não diferiram, sugerindo que os tratamentos não afetaram de imediato os componentes da parede celular. Os valores encontrados por FARIA et al. (1971) foram 23,2\% de FDN para o bagaço fresco, concordando com VAN SOEST (1994), que apresentou valores para o bagaço de laranja desidratado com $23 \%$ de FDN. Tal fato demonstra, mais uma vez, que existem diferenças entre os subprodutos, haja vista a variação existente entre as indústrias fornecedoras.

Após a abertura dos silos, os teores de FDN da silagem tratada com ácido fórmico foram os menores ( $\mathrm{P}<0,05)$, com comportamento quadrático (Tabela 3 ), enquanto os valores de FDN para a silagem sem aditivo (CT) sempre se mantiveram entre os mais elevados, concordando com os resultados apontados por MEGÍAS et al. (1993), que encontraram 20,3\% de FDN após 100 dias de ensilagem para o bagaço de laranja sem tratamento. ÍTAVO et al. (1998) obtiveram teores de FDN para o bagaço de laranja tratado com ácido fórmico, ensilado em tubos de concreto, de $22, \%$ e para a silagem sem aditivos, $24,6 \%$ de FDN.

Os aumentos numéricos dos valores de FDA apresentados (Tabela 4) são explicados pelo efeito de diluição do material, devido à perda de água e componentes solúveis por efluente do bagaço de laranja ensilado. Além do fato da possibilidade de ter ocorrido hidrólise ácida ou enzimática da hemicelulose, comentada por ROTZ e MUCK (1994), e no caso da silagem FO, a redução drástica dos teores de FDN sugere que podem ter ocorrido reações de Maillard, resultando na complexação da hemicelulose. A silagem tratada com ácido fórmico apresentou os menores valores de FDA (Tabela 4), praticamente para todos os tempos de abertura, enquanto o tratamento com aditivo enzimático microbiano permaneceu constante 
ÍTAVO et al.

Tabela 3 - Equações de regressão ajustadas para FDN da silagem de bagaço de laranja tratada ou não com aditivos, em função do dia (d) de abertura dos silos experimentais (\% MS)

Table 3 - Fitted regression equations for orange peel silage NDF with or without additives, in function of the open day (d) of the experimental silos (\% DM)

\begin{tabular}{llr}
\hline $\begin{array}{l}\text { Tratamento } \\
\text { Treatment }\end{array}$ & \multicolumn{1}{c}{$\begin{array}{c}\text { Equações de regressão } \\
\text { Regression equation }\end{array}$} & $\mathrm{R}^{2}$ \\
\hline N & $\hat{\mathrm{Y}}=19,9954+0,260953 \mathrm{~d}-0,0121212 \mathrm{~d}^{2}+0,000123933 \mathrm{~d}^{3}$ & 0,84 \\
FO & $\hat{\mathrm{Y}}=18,5698-0,116083 \mathrm{~d}+0,00125356 \mathrm{~d}^{2}$ & 0,70 \\
PP & $\hat{\mathrm{Y}}=20,0339+0,147586 \mathrm{~d}-0,0086646 \mathrm{~d}^{2}+0,0000977985 \mathrm{~d}^{3}$ & 0,62 \\
AC & $\hat{\mathrm{Y}}=19,6227+0,199895 \mathrm{~d}-0,00950364 \mathrm{~d}^{2}+0,000101801 \mathrm{~d}^{3}$ & 0,56 \\
CT & $\hat{\mathrm{Y}}=20,0331+0,421569 \mathrm{~d}-0,0232328 \mathrm{~d}^{2}+0,000258905 \mathrm{~d}^{3}$ & 0,96 \\
\hline
\end{tabular}

$\mathrm{IN}$ = inoculante enzimático microbiano; $\mathrm{FO}$ = ácido fórmico; PP = ácido propiônico; $\mathrm{AC}$ = ácido acético; $\mathrm{CT}=$ controle, sem aditivo

$I N=$ microbial enzymatic additive; $F O=$ formic acid; $P P=$ propionic acid; $A C=$ acetic acid $; C T=$ Control, without additive .

( $\mathrm{P}>0,05)$. Analisando o tratamento sem aditivo (CT), observa-se que este apresenta o maior valor inicial para os teores de FDA, sugerindo a ocorrência de hidrólise ácida da celulose nos tratamentos ácidos, como citado por ROTZ e MUCK, (1994). Apesar disso, os teores de FDA foram semelhantes àqueles registrados por MEGÍAS et al. (1993), que encontraram valores para FDA de 17,6\% após 100 dias de ensilagem, sendo, de maneira geral, inferiores aos apresentados por VAN SOEST (1994), que aponta valores de $22 \%$ de FDA para o bagaço de laranja desidratado e peletizado.

FARIA et al. (1971) encontraram 20,1\% de FDA, quando avaliaram o bagaço de laranja fresco, e BURGI (1986), 30,8\%. Porém, provavelmente, desconhecia-se a possibilidade de que essa porção da fibra poderia estar "contaminada" com pectina, portanto, tais valores poderiam ser menores, pois o valor de FDN foi 21,9\%, ou seja, um dos carboidratos mais digestíveis (pectina) estaria aumentando o valor de uma fração menos digestível (FDA).

DONAGHY e McKAY (1994) extraíram pectina do bagaço de laranja pelo método da poligalacturonase produzida no trigo. Segundo Hall (1995), citado por PERES (1997), não existe, ainda, uma análise química direta e única que permita a determinação da pectina dos alimentos. Isto pode ser explicado pela composição diversificada e pela provável presença de alguns açúcares nas frações menos digestíveis da parede celular. Esse autor argumenta ainda que a contaminação de outras frações fibrosas é o fator mais influi na completa extração da pectina, pois esta é obtida pela solução de detergente neutro, juntamente com os carboidratos não-estruturais, porém não é extraída completamente pela solução de detergente ácido, o que pode significar contaminação da FDA. Para solucionar tal problema, Hall (1995) citado por PERES (1997), recomenda a análise seqüencial entre detergen-

Tabela 4 - Equações de regressão ajustadas para FDA da silagem de bagaço de laranja tratada ou não com aditivos, em função do dia (d) de abertura dos silos experimentais (\% MS)

Table 4 - Fitted regression equations for orange peel silage ADF with or without additives, in function of the open day (d) of the experimental silos (\% DM)

\begin{tabular}{lcc}
\hline $\begin{array}{l}\text { Tratamento } \\
\text { Treatment }\end{array}$ & \multicolumn{1}{c}{$\begin{array}{c}\text { Equações de regressão } \\
\text { Regression equation }\end{array}$} & $\mathrm{R}^{2}$ \\
\hline IN & $\hat{\mathrm{Y}}=16,43482$ & $\mathrm{NS}$ \\
FO & $\hat{\mathrm{Y}}=14,6291+0,164938 \mathrm{~d}-0,0104306 \mathrm{~d}^{2}+0,000115503 \mathrm{~d}^{3}$ & 0,96 \\
PP & $\hat{\mathrm{Y}}=14,7510+0,498894 \mathrm{~d}-0,0210613 \mathrm{~d}^{2}+0,000212477 \mathrm{~d}^{3}$ & 0,90 \\
AC & $\hat{\mathrm{Y}}=14,5592+0,459873 \mathrm{~d}-0,0196808 \mathrm{~d}^{2}+0,000199979 \mathrm{~d}^{3}$ & 0,75 \\
CT & $\hat{\mathrm{Y}}=16,1784+0,315797 \mathrm{~d}-0,0168491 \mathrm{~d}^{2}+0,000182010 \mathrm{~d}^{3}$ & 0,97 \\
\hline
\end{tabular}

$\mathrm{IN}$ = inoculante enzimático microbiano; FO = ácido fórmico; PP = ácido propiônico; $\mathrm{AC}$ = ácido acético; $\mathrm{CT}=$ controle, sem aditivo.

NS = não-significativo $(P>0,05)$

$\mathbb{N}=$ microbial enzymatic additive; $F O=$ formic acid $P P=$ propionic acid; $A C=$ acetic acid; $C T=$ control, without additive $N S=$ non significant $(P>.05)$. 
1480 Rev. bras. zootec.

te neutro e detergente ácido como única alternativa.

$\mathrm{Na}$ Tabela 5, observa-se que, com exceção do tratamento com ácido fórmico, a digestibilidade da MS foi constante para os tratamentos e variou de $87,25 \%$, para o tratamento com ácido propiônico (PP), a 89,60\%, para o tratamento sem aditivo (CT), apresentando resultados superiores aos encontrados por DURAND et al. (1988) e Wainman e Dewey (1988), citados por CARVALHO (1995), que utilizaram a mesma técnica de simulação ruminal, com resultados para a digestibilidade in vitro da MS de 78 a $92 \%$.

O comportamento da DIVMS do tratamento com ácido fórmico (FO) foi linear negativo, iniciando em $90,82 \%$, substituindo-se a incógnita $\mathrm{d}(\mathrm{d}=0)$ na equação de regressão ajustada para a digestibilidade. Estes resultados estão de acordo com GORDON (1996), o qual argumentou que silagens tratadas com ácido fórmico poderiam ter valores mais elevados da digestibilidade in vitro da MS, sugerindo que o tratamento ácido afeta diretamente o valor nutritivo da silagem; não obstante, deve-se ressaltar que estes valores estão muito próximos dos valores obtidos com a silagem sem aditivo, sem diferença significativa entre suas médias $(\mathrm{P}>0,05)$. Os resultados apresentados na Tabela 5, referentes ao valores de digestibilidade in vitro da MS, estão de acordo aos apresentados por ASHBELL e LISKER (1987), que encontraram valores para a digestibilidade do bagaço fresco e ensilado variando de 88 a $92,9 \%$, os quais foram inferiores aos observados por ASHBELL e WEINBERG (1988), quando avaliou a digestibilidade in vitro da matéria seca do bagaço de laranja fresco

Tabela 5 - Equações de regressão ajustadas para DIVMS da silagem de bagaço de laranja tratada ou não com aditivos, em função do dia (d) de abertura dos silos experimentais

Table 5 - Fitted regression equations for the orange peel silage IVDMD with or without additives, in function of open day (d) of the experimental silos

\begin{tabular}{llc}
\hline $\begin{array}{l}\text { Tratamento } \\
\text { Treatment }\end{array}$ & $\begin{array}{c}\text { Equações de regressão } \\
\text { Regression equations }\end{array}$ & $\mathrm{R}^{2}$ \\
\hline IN & $\hat{\mathrm{Y}}=87,9236$ & $\mathrm{NS}$ \\
FO & $\hat{\mathrm{Y}}=90,8180-0,0717205 \mathrm{~d}$ & 0,65 \\
PP & $\hat{\mathrm{Y}}=87,2472$ & $\mathrm{NS}$ \\
AC & $\hat{\mathrm{Y}}=87,8444$ & $\mathrm{NS}$ \\
CT & $\hat{\mathrm{Y}}=89,59988$ & $\mathrm{NS}$
\end{tabular}

$\overline{\mathbb{N}}$ = inoculante enzimático microbiano; $\mathrm{FO}$ = ácido fórmico; $\mathrm{PP}=$ ácido propiônico; $\mathrm{AC}=$ ácido acético $; \mathrm{CT}=$ controle, sem aditivo . $\mathrm{NS}=$ não-significativo $(P>0,05)$.

$I N=$ microbial enzymatic additive; $F O=$ formic acid; $P P=$ propionic acid; $A C=$ acetic acid $; C T=$ control, without additive.

$N S=$ non significant $(P>05)$. e ensilado, registrando 92,6 e $92,5 \%$, respectivamente.

Os valores apresentados na Tabela 6, os quais variam entre 93,86, para o tratamento com ácido propiônico (PP), e 96,37\%, para o tratamento com inoculante enzimático microbiano (IN), sugerem o alto aproveitamento da silagem de bagaço de laranja, provavelmente devido aos baixos valores de lignina no bagaço, resultando em alta digestibilidade. Quanto aos resultados da digestibilidade in vitro da FDN, Wainman e Dewey, (1988), citados por CARVALHO (1995), apresentam resultados de 90 a 92\%, inferiores aos resultados apresentados na Tabela 6, o que sugere a existência de diferenças entre os teores de lignina das silagens citadas e, por conseguitne, entre as composições do bagaço de laranja. BROWN e JOHNSON (1991) apresentaram valores abaixo dos de digestibilidade in vitro da FDN do bagaço de laranja, $75,8 \%$. A partir do $16^{\circ}$ dia de ensilagem, os tratamentos não apresentaram diferenças $(\mathrm{P}<0,05)$, demonstrando a ausência do efeito do aditivo na digestibilidade in vitro da FDN, sugerindo que, após 16 dias de ensilado, o bagaço de laranja já se encontra estável, o que também pode ser notado pelos valores referente ao $\mathrm{pH}$ das silagens.

Na Tabela 7, estão apresentados os valores referentes ao comportamento do $\mathrm{pH}$ das silagens em função do dia de abertura dos silos. Constata-se que, praticamente, não houve diferença entre os tratamentos, porém, dentro de cada tratamento, houve diferença entre os valores, ocorrendo diminuição com o passar do tempo, comparando-se o valor inicial $(\mathrm{d}=0)$ e o valor final $(\mathrm{d}=64)$ das equações de regressão ajustadas para o $\mathrm{pH}$; portanto, infere-se que houve fermentação adequada para a conservação das silagens.

$\mathrm{O}$ tratamento com ácido fórmico (FO) surtiu efeito imediatamente após a aplicação, baixando o pH do bagaço de laranja para 3,5, comprovando, assim, a teoria de Virtaneen, o qual postula que os aditivos ácidos deveriam reduzir o $\mathrm{pH}$ da massa ensilada para 3,5 (McDONALD, 1981). Após dois dias de ensilagem, já não houve diferença entre os tratamentos $(\mathrm{P}>0,05)$, sugerindo que ocorreu fermentação dos carboidratos solúveis do bagaço de laranja, enriquecendo o meio com produtos da fermentação, como o ácido láctico, ou, provavelmente, o ácido fórmico, quem além de ser um ácido forte, possui também atividade bactericida seletiva. Portanto, pode ocorrer queda do $\mathrm{pH}$, sem aumento do ácido láctico. FARIA et al. (1971) encontraram valores para porcentagens de carboidratos solúveis na MS de bagaço de laranja entre 37,1 e 43,2\% e FARIA 
ÍTAVO et al.

Tabela 6 - Equações de regressão ajustadas para DIVPC da silagem de bagaço de laranja tratada ou não com aditivos, em função do dia (d) de abertura dos silos experimentais

Table 6 - Fitted regression equations for the orange peel silage IVCWD with or without additives, in function of the open day (d) of the experimental silos

\begin{tabular}{lcr}
\hline $\begin{array}{l}\text { Tratamento } \\
\text { Treatment }\end{array}$ & $\begin{array}{c}\text { Equações de regressão } \\
\text { Regression equations }\end{array}$ & $\mathrm{R}^{2}$ \\
\hline IN & $\hat{\mathrm{Y}}=96,3705-0,356671 \mathrm{~d}+0,0150045 \mathrm{~d}^{2}-0,000164761 \mathrm{~d}^{3}$ & 0,88 \\
FO & $\hat{\mathrm{Y}}=96,0559-0,054621 \mathrm{~d}+0,0023627 \mathrm{~d}^{2}-0,000021336 \mathrm{~d}^{3}$ & 0,66 \\
PPY & $\hat{\mathrm{Y}}=94,3658+0,168675 \mathrm{~d}-0,0108616 \mathrm{~d}^{2}+0,000134825 \mathrm{~d}^{3}$ & 0,94 \\
AC & $\hat{\mathrm{Y}}=93,8610+0,334995 \mathrm{~d}-0,0133494 \mathrm{~d}^{2}+0,000125523 \mathrm{~d}^{3}$ & 0,88 \\
CT & $\hat{\mathrm{Y}}=94,4436-0,004117378 \mathrm{~d}+0,000154202 \mathrm{~d}^{2}$ & 0,71 \\
\hline
\end{tabular}

$\mathrm{IN}$ = inoculante enzimático microbiano; $\mathrm{FO}=$ ácido fórmico; $\mathrm{PP}=$ ácido propiônico; $\mathrm{AC}=$ ácido acético; $\mathrm{CT}=$ controle, sem aditivo.

$\mathbb{I N}=$ microbial enzymatic additive $; F O=$ formic acid $; P P=$ propionic acid $; A C=$ acetic acid $; C T=$ control, without additive

et al. (1972), utilizando o bagaço de laranja fresco como aditivo na ensilagem do capim-elefante, de 39,3\%.

Os resultados apresentados na Tabela 7 mostram que o $\mathrm{pH}$ inicial do bagaço de laranja sem aditivo foi de 4,3, com exceção do tratamento com ácido fórmico, concordando com os resultados da literatura (ASHBELL e DONAHAYE, 1986; ASHBELL et al., 1987; ASHBELL e LISKER, 1987; ASHBELL e WEINBERG, 1988; WEINBERG et al., 1989; e TAIWO et al., 1995), nos quais o pH do bagaço de laranja, antes de ensilar, varia de 4,2 a 4,9. Ao final de 64 dias de ensilagem, o pH foi 3,3, em média, sem apresentar diferenças $(\mathrm{P}>0,05)$ entre os tratamentos, sugerindo que o bagaço de laranja é rico em carboidratos solúveis responsáveis pela queda do $\mathrm{pH}$, em consequiência de sua fermentação, e os tratamentos não apresentam efeitos no $\mathrm{pH}$ final da silagem, de acordo com a literatura, que cita valores de $\mathrm{pH}$ variando de 3,3 a 3,9 na silagem de bagaço de laranja (ASHBELL e DONAHAYE, 1986; ASHBELL et al., 1987; ASHBELL e LISKER, 1987; ASHBELL e WEINBERG, 1988; WEINBERG et al., 1989; e TAIWO et al., 1995).
Os valores do $\mathrm{pH}$ das silagens (Tabela 7) foram superiores aos de MEGÍAS et al. (1992), que utilizaram quantidades inferiores de ácido fórmico (a $4 \%$, $62,5 \mathrm{~mL} / \mathrm{kg}$ de $\mathrm{MN}$ ) e encontraram valores de 2,7 para o tratamento com ácido fórmico e 3,0 para o bagaço sem tratamento com aditivos, sugerindo a ocorrência de diferenças entre os subprodutos utilizados por MEGÍAS et al. (1992) e os obtidos neste experimento.

Após dois dias de ensilagem, a silagem CT já apresentava valores semelhantes aos das silagens IN, PP e AC, sugerindo que houve alta fermentação dos carboidratos solúveis. Para o rápido declínio do $\mathrm{pH}$, é imprescindível que exista, no meio, quantidade suficiente de carboidratos solúveis fermentescíveis e a capacidade tampão seja baixa de tal maneira que não impeça tal diminuição de pH para os níveis desejados. Isso sugere que o bagaço de laranja possui características desejáveis para obter boa silagem. WOOLFORD (1990) relatou que alto teor de umidade, alta capacidade tampão e baixos teores de carboidratos solúveis são fatores que podem influir no processo de ensilagem e, negativamente, no processo fermentativo, impedindo o rápido decréscimo do $\mathrm{pH}$, favorecendo,

Tabela 7 - Equações de regressão ajustadas para $\mathrm{pH}$ da silagem de bagaço de laranja tratada ou não com aditivos, em função do dia (d) de abertura dos silos experimentais

Table 7 - Fitted regression equations for the orange peel silage $\mathrm{pH}$ with or without additives, in function of the open day (d) of the experimental silos

\begin{tabular}{lcr}
\hline $\begin{array}{c}\text { Tratamento } \\
\text { Treatment }\end{array}$ & $\begin{array}{c}\text { Equações de regressão } \\
\text { Regression equations }\end{array}$ & $\mathrm{R}^{2}$ \\
\hline $\mathrm{IN}$ & $\hat{\mathrm{Y}}=96,3705-0,356671 \mathrm{~d}+0,0150045 \mathrm{~d}^{2}-0,000164761 \mathrm{~d}^{3}$ & 0,88 \\
$\mathrm{IN}$ & $\hat{\mathrm{Y}}=4,16199-0,0972870 \mathrm{~d}+0,00358601 \mathrm{~d}^{2}-0,0000352169 \mathrm{~d}^{3}$ & 0,65 \\
$\mathrm{FO}$ & $\hat{\mathrm{Y}}=3,51802-0,00282602 \mathrm{~d}$ & 0,89 \\
$\mathrm{PP}$ & $\hat{\mathrm{Y}}=4,26777-0,113436 \mathrm{~d}+0,00399025 \mathrm{~d}^{2}-0,0000382835 \mathrm{~d}^{3}$ & 0,77 \\
$\mathrm{AC}$ & $\hat{\mathrm{Y}}=4,17717-0,0896931 \mathrm{~d}+0,00309419 \mathrm{~d}^{2}-0,000029642 \mathrm{~d}^{3}$ & 0,79 \\
$\mathrm{CT}$ & $\hat{\mathrm{Y}}=4,33407-0,116987 \mathrm{~d}+0,00401959 \mathrm{~d}^{2}-0,0000381311 \mathrm{~d}^{3}$ & 0,75 \\
\hline $\mathrm{N}=$ inoculante enzimático microbiano; $\mathrm{FO}=$ ácido fórmico; $\mathrm{PP}=$ ácido propiônico; $\mathrm{AC}=$ ácido acético; \\
$\mathrm{CT}=$ controle, sem aditivo. \\
$\mathbb{I N}=$ microbial enzymatic additive; $F O=$ formic acid; $P P=$ propionic acid; $A C=$ acetic acid; $C T=$ control, without additive.
\end{tabular}


1482 Rev. bras. zootec.

Tabela 8 - Equações de regressão ajustadas para nitrogênio amoniacal da silagem de bagaço de laranja tratada ou não com aditivos, em função do dia (d) de abertura dos silos experimentais. (\% do $\mathrm{N}$ total)

Table 8 - Fitted regression equations for the orange peel ammonia silage nitrogen with or without additives, in function of the open day (d) of the experimental silos (\% of $N$ total)

\begin{tabular}{lcc}
\hline $\begin{array}{l}\text { Tratamento } \\
\text { Treatment }\end{array}$ & \multicolumn{1}{c}{$\begin{array}{c}\text { Equações de regressão } \\
\text { Regression equations }\end{array}$} & $\mathrm{R}^{2}$ \\
\hline $\mathrm{IN}$ & $\hat{\mathrm{Y}}=96,3705-0,356671 \mathrm{~d}+0,0150045 \mathrm{~d}^{2}-0,000164761 \mathrm{~d}^{3}$ & 0,88 \\
$\mathrm{IN}$ & $\hat{\mathrm{Y}}=3,772069$ & $\mathrm{NS}$ \\
$\mathrm{FO}$ & $\hat{\mathrm{Y}}=2,5511-0,0205176 \mathrm{~d}+0,00173661 \mathrm{~d}^{2}+0,0000210274 \mathrm{~d}^{3}$ & 0,99 \\
$\mathrm{PP}$ & $\hat{\mathrm{Y}}=3,01247+0,116484 \mathrm{~d}-0,00382177 \mathrm{~d}^{2}+0,00003668 \mathrm{~d}^{3}$ & 0,92 \\
$\mathrm{AC}$ & $\hat{\mathrm{Y}}=2,87805+0,158909 \mathrm{~d}-0,00508274 \mathrm{~d}^{2}+0,0000461615 \mathrm{~d}^{3}$ & 0,85 \\
$\mathrm{CT}$ & $\hat{\mathrm{Y}}=3,634213$ & $\mathrm{NS}$ \\
\hline $\mathrm{IN}=$ & Inoculante enzimático microbiano; $\mathrm{FO}=$ ácido fórmico; $\mathrm{PP}=$ ácido propiônico; $\mathrm{AC}=$ ácido acético; \\
& $\mathrm{CT}=$ controle, sem aditivo; $\mathrm{NS}=$ não-significativo $(\mathrm{P}>0,05)$ & \\
$\mathrm{IN}=$ & microbial enzymatic additive; $F O=$ formic acid; $P P=$ propionic acid; $A C=$ acetic acid; $C T=$ control, without additive; \\
& $\mathrm{NS}=$ non significant $(P>$. O5)
\end{tabular}

assim, fermentações secundárias indesejáveis.

A capacidade tampão determina, aproximadamente, a quantidade de fermentação ácida para alcançar determinado $\mathrm{pH}$. Os valores referentes à capacidade tampão das silagens, em função do tempo (em dias) de abertura dos silos, estão apresentados na Tabela 8. Em geral, a capacidade tampão para o milho são as menores, ou seja, de 15 a 25 e.mg de $\mathrm{HCl} / 100 \mathrm{~g}$ MS (McDONALD, 1981). Os valores para o bagaço de laranja foram de 25,7 a 36,5 antes da ensilagem, 39,1 para o tratamento com ácido fórmico (FO) e 58,4 a 63,4 e.mg HCl/100g MS para os demais tratamentos após 64 dias de ensilagem, sugerindo que pode ter ocorrido pouca atividade fermentativa, devido aos elementos tamponantes, apesar do alto conteúdo de carboidratos solúveis e, consequientemente, à baixa produção de ácido láctico, todavia, deve ser salientado que o $\mathrm{pH}$ inicial do bagaço de laranja é baixo e quase atinge o necessário para cessar qualquer atividade microbiana.

Durante a ensilagem, a dissociação dos ácidos orgânicos do material seria benéfica para reduzir a atividade tamponante, porém a fermentação repõe ácidos com propriedades tamponantes fortes. A formação de íons, combinados com ácidos provenientes da fermentação, formam novos sistemas tamponantes. TAIWO et al. (1995) apresentaram valores da capacidade tampão da silagem de bagaço de laranja sem aditivos de 11,6, 25,8 e 40,8 e.mg HCl/ $100 \mathrm{~g}$ MS, para o material ensilado por 21, 28 e 61 dias, respectivamente. O comportamento da capacidade tampão da silagem de bagaço de laranja, apresentada por TAIWO et al. (1995), está de acordo com os resultados apresentados na Tabela 9, apesar de superiores.
O bagaço de laranja, tratado com ácido fórmico (FO), foi o que apresentou os menores valores para a capacidade tampão durante todo o experimento $(\mathrm{P}<0,05)$, sugerindo que, após a aplicação do ácido, ocorreu diminuição dos elementos tamponantes da silagem, porém há de se salientar que a avaliação da capacidade tampão de silagens é feita por e.mg de $\mathrm{HCl}$, portanto, se o material já está acidificado com ácido forte, esperar-se-iam menores valores para a capacidade tampão em relação às silagens tratadas com ácido fraco ou não-tratadas.

$\mathrm{O}$ nitrogênio amoniacal de uma silagem tem estreita relação com a proteólise ocorrida dentro do ambiente do silo. Segundo HENDERSON (1993), sob boas condições de umidade, a MS da silagem aumenta e os açúcares ficam concentrados na MS, contudo, pode ocorrer deaminação de alguns aminoácidos e o nitrogênio protéico pode ser reduzido. Se isso ocorrer, a silagem provavelmente terá alto conteúdo de $\mathrm{N}$ amoniacal, mesmo com a utilização de aditivos na silagem. Geralmente, é aceitável que uma silagem bem conservada apresente conteúdo de $\mathrm{N}$ amoniacal menor que $8 \%$ do $\mathrm{N}$ total.

Os valores de $\mathrm{N}$ amoniacal observados neste experimento (Tabela 9) não ultrapassaram $4 \%$ de $\mathrm{N}$ amoniacal em relação ao $\mathrm{N}$ total, por conseguinte, a silagem pode ser considerada de boa qualidade, independente do uso de aditivos, concordando com o critério apontado por HENDERSON (1993).

Os efeitos do ácido fórmico na fermentação têm mostrado que seu uso resulta na redução da fermentação, com pequenas proporções de ácidos, acético e butírico e reduzida proteólise, na silagem resultante (GORDON, 1996). Ainda, o uso do aditivo ácido 
ÍTAVO et al.

Tabela 9 - Equações de regressão ajustadas para capacidade tamponante da silagem de bagaço de laranja tratada ou não com aditivos, em função do dia (d) de abertura dos silos experimentais (e.mg HCl/100 g MS)

Table 9 - Fitted regression equations for the orange peel silage buffering capacity with or without additives, in function of the open day (d) of the experimental silos. (meq. $\mathrm{HCl} / 100 \mathrm{~g} \mathrm{DM}$ )

\begin{tabular}{lcr}
\hline $\begin{array}{l}\text { Tratamento } \\
\text { Treatment }\end{array}$ & $\begin{array}{c}\text { Equações de regressão } \\
\text { Regressionequations }\end{array}$ & $\mathrm{R}^{2}$ \\
\hline IN & $\hat{\mathrm{Y}}=31,5109+1,71225 \mathrm{~d}-0,0189711 \mathrm{~d}^{2}$ & 0,56 \\
FO & $\hat{\mathrm{Y}}=25,7371+0,498382 \mathrm{~d}-0,00452687 \mathrm{~d}^{2}$ & 0,67 \\
PP & $\hat{\mathrm{Y}}=36,4911+1,54321 \mathrm{~d}-0,0178803 \mathrm{~d}^{2}$ & 0,68 \\
AC & $\hat{\mathrm{Y}}=35,1926+1,70262 \mathrm{~d}-0,204513 \mathrm{~d}^{2}$ & 0,62 \\
CT & $\hat{\mathrm{Y}}=31,9848+1,4734 \mathrm{~d}-0,01657 \mathrm{~d}^{2}$ & 0,65 \\
\hline
\end{tabular}

$\mathrm{N}$ = inoculante enzimático microbiano; FO = ácido fórmico; PP = ácido propiônico; $\mathrm{AC}$ = ácido acético; $\mathrm{CT}=$ controle, sem aditivo .

$I N=$ microbial enzymatic additive $; F O=$ formic acid $P P=$ propionic acid $; A C=$ acetic acid $; C T=$ Control, without additive.

promoveu $\mathrm{pH}$ baixo e $6 \%$ de $\mathrm{N}$ amoniacal em relação ao $\mathrm{N}$ total, sugerindo que o aditivo fornece bons parâmetros para uma boa silagem, que pode ser notado pelas equações de regressão ajustadas, apresentadas na Tabela 9. Todavia, o tratamento FO foi o que apresentou os maiores valores $(\mathrm{P}<0,05)$ em relação às demais silagens, a partir do $2^{\circ}$ dia de ensilagem, explicando as diferenças dos teores de MS e PB, sugerindo que houve perdas, apesar das porcentagens satisfatórias.

O inoculante enzimático microbiano (IN) e o bagaço de laranja sem aditivo (CT) apresentaram valores satisfatórios e constantes, quanto ao $\mathrm{N}$ amoniacal, resultando em boa conservação do material, concordando com GORDON (1996), o qual afirma que tais inoculantes têm melhorado a qualidade fermentativa das silagens, principalmente pela redução do $\mathrm{N}$ amoniacal. Entretanto, ÍTAVO et al. (1998) apresentaram valores de NIDA e carboidratos não-estruturais sem diferença significativa para a silagem de bagaço de laranja tratada ou não com aditivo enzimático microbiano.

\section{Conclusões}

O bagaço de laranja pode ser eficientemente conservado sob a forma de silagem sem o uso de aditivos. A aplicação de aditivos, ácidos ou enzimático microbiano, não melhoram os parâmetros de fermentação das silagens ao ponto de para recomendá-los para a confecção da silagem de bagaço de laranja, porém ainda são necessários mais estudos quanto aos aditivos ácidos na ensilagem do bagaço de laranja com relação as quantidades e concentrações de tais ácidos.

\section{Referências Bibliográficas}

AMMERMAN, C.B., HENRY, P.R. 1991. Citrus and vegetable products for ruminants animals. Feeding and nutrition. Florida: University of Florida. p.103-190.

ASHBELL, G. Conservation of citrus peel by ensiling for ruminant feed In: SIMPÓSIO UTILIZAÇÃO DE SUBPRODUTOS AGRO-INDUSTRIAIS E RESÍDUOS DE COLHEITA NA ALIMENTAÇÃO DE RUMINANTES, 1992, São Carlos, SP. Anais...São Carlos: EMBRAPA/UEPAE. 1992. p.189-190.

ASHBELL, G. The potential for high quality silage production from homegrown forage and by-products in Israel. In: AGRICULTURAL RESEARCH ORGANIZATION, 1987, Bet Dagan, Israel. Proceedings... Bet Dagan: The Volcani Center. 1987. p.153-160.

ASHBELL, G., DONAHAYE, E. 1984. Losses in orange peel silage. Agric. Wastes, 11:73-77.

ASHBELL, G., DONAHAYE, E. 1986. Laboratory trials on conservation of orange peel silage. Agric. Wastes, 15:133-137.

ASHBELL, G., LISKER, N. 1987. Chemical and microbiological changes occurring in orange peel and in the seepage during ensiling. Biol. Wastes, 21:213-220.

ASHBELL, G., PAHLOW, G., DINTER, B. et al. 1987. Dynamics of orange peel fermentation during ensilage. J. Applied Bact., 63:275-279.

ASHBELL, G., WEINBERG, Z.G. 1988. Orange peels: The effect of blanching and calcium hidroxide addition on ensiling losses. Biol. Wastes, 23:73-77.

BRANCO, A.F., ZEOULA, L.M., PRADO, I.N. et al. 1994. Valor nutritivo da polpa de citrus in natura para ruminantes. Rev. Unimar, 16(1):37-48.

BROWN, W.F., JOHNSON, D.D. 1991. Effects of energy and protein supplementation of ammoniated tropical grass hay on the growth and carcass characteristics of cull cows. $J$. Anim. Sci., 63:348-357.

BURGI, R. Utilização de resíduos agro-industriais na alimentação de ruminantes. In: CONGRESSO BRASILEIRO DE PASTAGENS E SIMPÓSIO SOBRE MANEJO DA PASTAGEM, 8. Piracicaba, SP. 1986. Anais...Piracicaba:FEALQ, p.101-117. 1986

CARVALHO, M.P. Citros. In: SIMPÓSIO SOBRE NUTRIÇÃO DE BOVINOS, 6, 1995, Piracicaba, SP, 1995. Anais...Piracicaba: FEALQ. p.171-214. 1995.

DONAGHY, J.A., McKAY, A.M. 1994. Pectin extraction from citrus peel by polygalacturonase produced on whey. Bioresource Technology, 47:25-28. 
1484 Rev. bras. zootec.

DURAND, M., DUMAY, C., BEAUMATIN, P. et al. 1988. Use of rumen simulation technique (rusitec) to compare microbial digestion of various by-products. Anim. Feed Sci. Technol., 21(2-4):197-204.

FARIA, V.P., TOSI, H., SILVEIRA, A.C. 1971. Avaliação da polpa de laranja fresca e ensilada como alimento para bovinos. O Solo, 63(2):49-55.

FARIA, V.P., TOSI, H., GODOY, C.R.M. 1972. Polpa de laranja fresca e seca como aditivos para a ensilagem do capim elefante napier. O Solo, 64(1):41-47.

GOERING, H.K., VAN SOEST, P.J. 1970. Forage fiber analysis. Handbook n.379, Agricultural Research Service, USDA, Washington, D.C. p.210-212.

GORDON, F.J. 1996. Effect of silage additives and wilting on animal performance In: GARNSWORTHY, P.C., COLE, D.J.A. (Eds.) Recent developments in ruminant nutrition 3.ed., Nottingham: University Press. p.229-244.

HENDERSON, N. 1993. Silage additives. Anim. Feed Sci. Technol., 45(1):35-56.

ÍTAVO, L.C.V., SANTOS, G.T., JOBIM, C.C. et al. Consumo e digestibilidade aparente da silagem de bagaço de laranja. In: REUNIÃO DA SOCIEDADE BRASILEIRA DE ZOOTECNIA, 35, 1998. Anais...Botucatu, SP. p.388-390. 1998.

McDONALD, P. 1981. The biochemistry of silage. New York: Ed. John Wiley \& Sons Ltda. 207p.

MEGÍAS, M.D., GALLEGO, J.A., MARTINEZ-TERUEL, A. et al. 1992. Estudio comparativo de diferentes aditivos en el ensilado del subproducto de naranja.Arch.Zootec., 41:179-182.

MEGÍAS, M.D., MARTINEZ-TERUEL, A., GALLEGO, J.A. et al. 1993. Chemical changes during the ensiling of orange peel. Anim. Feed Sci. Technol., 43:269-274.

MORRISON, F.B. 1966. Alimentos e alimentação dos animais. 2.ed., São Paulo: Edições Melhoramentos. 892p.

PERES, J.R. Avaliação da polpa de citrus seca e peletizada como aditivo na ensilagem do capim elefante (Pennisetum purpureum, Schum). Piracicaba, SP, ESALQ-USP, 1997. 71p. Dissertação (Mestrado em Agronomia) - Escola Superior de Agricultura Luiz de Queiroz - Universidade de São Paulo, 1997.

PLAYNE, M.J., McDONALD, P. 1966. The buffering constituents of herbage and silage. J. Sci. Food. Agric., 17(2):262-268.
REGAZZI, A.J. 1993. Teste para verificar a identidade de modelos de regressão e a igualdade de alguns parâmetros num modelo polinomial ortogonal. Rev. Ceres, 40(228):176-195.

ROTZ, C.A., MUCK, R.E. Changes in forage quality during harvest and storage. In: NATIONAL CONFERENCE ON FORAGE QUALITY. EVALUATION AND UTILIZATION, 1994. University of Nebraska. Proceedings... Lincoln. p.828-868. 1994.

RUIZ, R.L., MUNARI, D.P. 1992. Microbiologia da silagem. In: RUIZ, R.L. (Ed.) Microbiologia zootécnica. São Paulo: Ed. Roca. p.97-122.

SANTOS, G.T., ASSIS, M.A., PETIT, H.V. et al. 1997. Chemical composition and in situ degradability of leucaena (Leucaena leucocephala) and desmodium (Desmodium ovalifolium) submitted at two conservation forms. J. Dairy Sci., 80:221 (Suppl. 1).

SILVA, D.J. 1990. Análise de alimentos (Métodos químicose biológicos). Viçosa: UFV, Imprensa Universitária. 165p.

TAIWO, A.A., ADEBOWALE, E.A., GREENHALGH, J.F.D. et al. 1995. O. Techniques for trapping ammonia generated from urea treatment of barley straw. Anim. Feed Sci. Technol., 56:133-141.

VAN SOEST, P.J. 1994. Nutritional ecology of the ruminant. Ithaca: Comstock Publ. Assoc. 476p.

WEINBERG, Z.G. Bioconservation of agricultural by-products by ensiling In: SIMPÓSIO UTILIZAÇÃO DE SUBPRODUTOS AGRO-INDUSTRIAIS E RESÍDUOS DE COLHEITA NA ALIMENTAÇÃO DE RUMINANTES, 1992. São Carlos, SP. Anais... São Carlos: EMBRAPA/ UEPAE, 1992. p.191-197.

WEINBERG, Z.G., ASHBELL, G., HOREV, B. 1989. The effect of sorbic acid on loss reduction during storage of orange peels. J. Sci. Food Agric., 46:253-258.

WOOLFORD, M.K. 1990. A Review:The detrimental effects of air on silage. J. Applied Bact., 68:101-116.

Recebido em: 18/06/1998

Aceito em: 31/04/2000 